OAkley, W.G., Pyke, D.A. \& TAylor, K.W. (1968) Clinical Diabetes and its Biochemical Basis, p. 300. Blackwell Scientific Publications, Oxford.

Rapoport, A., From, G.L.A. \& Husdan, H. (1965) Metabolic studies in prolonged fasting. I. Inorganic metabolism and kidney function. Metabolism, 14, 31 .

Rooth, G. \& Carlström, S. (1970) Therapeutic fasting. Acta medica scandinavica, 187, 455.

Runcie, J. \& Thomson, T.J. (1970) Prolonged starvation-a dangerous procedure? British Medical Journal, 3, 432.

Schless, G.L. \& Duncan, G.G. (1966) The beneficial effect of intermittent total fasts on the glucose tolerance in obese diabetic patients. Metabolism, 15, 98 .

SPENCER, I.O.B. (1968) Death during therapeutic starvation for obesity. Lancet, i, 1288.
Stewart, W.K., Fleming, L.W. \& Robertson, P.C. (1966) Massive obesity treated by intermittent fasting: A metabolic and clinical study. American Journal of Medicine, 40, 967.

Stewart, W.K. \& Fleming, L.W. (1969) Fragmentation of cardiac myofibrils after therapeutic starvation. Lancet, i, 1154.

Thomson, T.J., Runcie, J. \& Miller, V. (1966) Treatment of obesity by total fasting for up to 249 days. Lancet, ii, 992.

Wildenhoff, K.E., Dalsager, H.H. \& Schwartz SørenSEN, N. (1969) Ketonstoffer i blod og urin hos overvaegtige patienter behandlet med absolut faste. Nordisk Medicin, 82, 1201 .

\title{
Tumours of the sigmoid colon following ureterosigmoidostomy
}

\author{
W. M. LIEN \\ M.B., Ch.B., F.R.C.S.
}

Department of Urology, The Queen Elizabeth Hospital, Birmingham B15 2TH

\begin{abstract}
Summary
A case of bilateral adenomatous polyps and a case of adenocarcinoma of the sigmoid colon following ureterosigmoidostomy are described. The recent literature is reviewed. The possible causes and the mucosal changes of the large bowel after ureterosigmoidostomy are briefly discussed.

NeOPLASIA complicating ureterosigmoidostomy is an uncommon but well recognized entity. The number of cases reported in individual series has been small. In 1967, Kille \& Glick reported two cases from this hospital, those being the eighteenth and nineteenth cases documented in the world literature. Two further cases from this unit are now reported.
\end{abstract}

\section{Case 1}

A 25-year-old female was born with ectopia vesicae. Ureterosigmoidostomy and total cystectomy were carried out at the age of $1 \frac{1}{2}$ years. She was well clinically, radiologically and biochemically until 1967 when she developed left renal pain. An IVP showed some dilatation of the left renal tract. As she was taking contraceptive pills, it was considered that this could be a hormonal effect similar to that described by Marshall, Lyon \& Minkler (1966). She was advised to stop the 'pill' and an IVP was repeated 6 months later, but by this time considerable bilateral hydronephrosis had developed. In September 1968, she was admitted for re-implantation of the ureters. At operation two groups of polyps, each measuring $3.5 \times 2.5 \mathrm{~cm}$ were found, one at the site of each ureterocolic anastomosis. These were

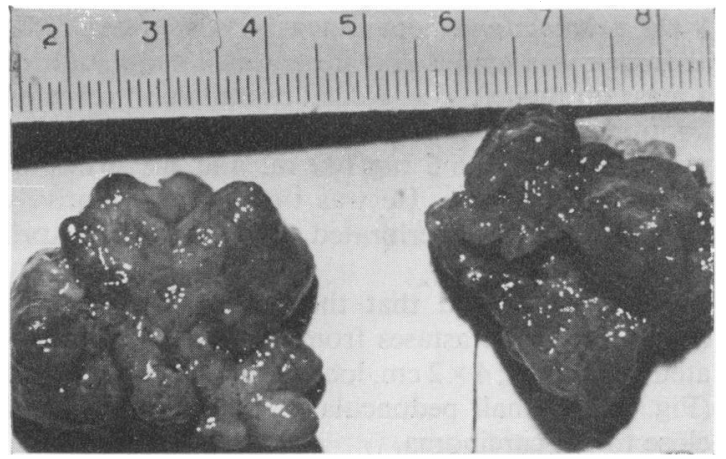

FIG. 1. Two groups of adenomatous polyps excised from Case 1. Scale in $\mathrm{cm}$.

excised (Fig. 1). The ureters were re-implanted into the rectum to form a rectal bladder and a terminal iliac colostomy was fashioned.

Histology showed that the polyps appeared to be simple adenomata but the possibility of mucoid carcinoma could not be excluded. She did extremely well. The appearance on her IVP returned to normal except for a small area of pyelonephritic scarring at the lower pole of the left kidney. She was delivered of a healthy infant by Caesarean section 2 years later. Her urine is sterile and biochemistry normal.

\section{Case 2}

A 33-year-old man sustained a comminuted fracture of the pelvis, with extraperitoneal rupture of the bladder and urethra in 1941, at the age of 4 years. Almost moribund on admission to another hospital, 
he was transfused with blood and a suprapubic catheter inserted. Subsequent attempts to repair the urethra were unsuccessful. In 1944, ureterosigmoidostomy was carried out. By 1946, he had developed bilateral hydronephrosis and the ureterocolic anastomosis was refashioned. Between 1953 and 1956 he experienced intermittent attacks of passage of blood per rectum. Sigmoidoscopy and barium enema revealed no abnormality. An IVP in 1956 showed absence of left renal excretion up to $3 \mathrm{hr}$ postinjection of contrast material. Right hydronephrosis and hydroureter were also present. In 1957 , the ureterosigmoidostomy was converted to a ureteroileostomy. In 1960, a large staghorn calculus developed in his right kidney. This stone was removed in 1963. At operation, the tissues were found to be adherent and oedematous; in spite of T-tube drainage a fistula developed and persisted. In 1969, barium enema revealed a narrow segment at the site of previous ureterosigmoidostomy but sigmoidoscopy to $16 \mathrm{~cm}$ revealed no abnormality. His blood urea was $94 \mathrm{mg} / 100 \mathrm{ml}$. On his final admission in March 1971, he complained of bilateral loin pain, foulsmelling urine and constipation for 3 weeks.

On examination, hepatomegaly was present, the abdomen was tender and there was a suggestion of a mass on the left side. Rectal examination revealed no tumour. His blood urea was $264 \mathrm{mg} / 100 \mathrm{ml}$, serum creatinine $6.6 \mathrm{mg} / 100 \mathrm{ml}$ and his urine infected with Proteus. He was treated conservatively but his condition deteriorated and he died on 5 April 1971.

Necropsy showed that the liver was extensively infiltrated by metastases from a large craggy ulcerated carcinoma, $4 \times 2 \mathrm{~cm}$, located in the rectosigmoid (Fig. 2). A small pedunculated polyp was situated close to the carcinoma.

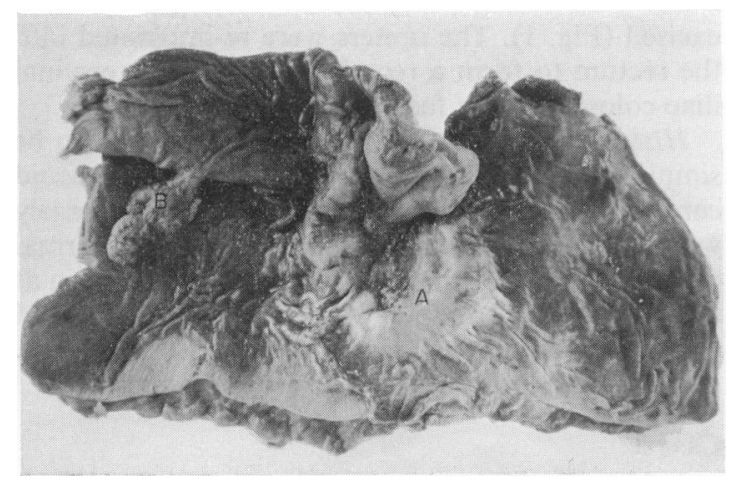

FIg. 2. Necropsy specimen from Case 2. A, ulcerating adenocarcinoma of sigmoid colon; $\mathbf{B}$, adenomatous polyp.

\section{Discussion}

Both Kozak, Watkins \& Jewell (1966) and Urdaneta et al. (1966) reviewed the world literature and Kille \& Glick analysed the published cases in detail. Since Kille \& Glick's paper there have only been nine further cases reported in the world literature. Markowitz \& Koontz (1966) described three cases of adenomatous 'juvenile' polyps developing at the site of ureteral implantation. Richter \& Ginsberg (1967) described a case of adenocarcinoma of the colon occurring at the ureterosigmoidostomy site, with extension to the distal part of the left ureter. MacGregor (1968) reported a case of mucussecreting adenomatous polyp at the site of ureterosigmoidostomy. Oetjen et al. (1970) reported a case of adenocarcinoma of the colon 23 years after ureterosigmoidostomy performed for exstrophy of the bladder. Finally, Whittaker, Pugh \& Dow (1971) reported three cases of carcinoma, but their first case has previously been described briefly by another author. Including the two cases presented in this paper, there are now thirty cases documented in the world literature.

The aetiology of these tumours is still a matter of conjecture. The cause may be mechanical, as recurrent trauma produced by faecal stream passing over the mucosal mound formed by the ureteral stoma may induce destruction and regeneration of epithelium. Sommo \& Traverso (1968) used histochemical methods for evaluating mucopolysaccharides. They examined the changes in the rectal mucosa following ureterosigmoidostomy and found the earliest alteration to be a blockage in the secretion of mucus. This was followed by a stage of proliferation, affecting mainly the glandular element, and finally there was a stage of atrophy. Irritation of the colonic mucosa by urine has been blamed. Carcinogens may be present in the urine and this may provoke a neoplastic change in the bowel mucosa, but the work of Scott \& Boyd (1953) showed that the colonic mucosa is highly resistant to malignant degeneration when exposed to urinary carcinogen, at least in dogs.

The most common presenting symptoms are rectal bleeding, intestinal obstruction and loin pain. This has been emphasized by previous authors (Kille \& Glick, 1967; Kozak, Watkins \& Jewell, 1966). The two cases in this paper followed this pattern. Kille \& Glick (1967) pointed out that the latent period between ureterosigmoidostomy and development of tumours was between 10-31 years when the original operation was performed for a benign disorder, and between 5-9 years when the original operation was performed for malignancy. The latent periods in our two cases were 20 and 27 years respectively. During the follow-up of these patients it is important for us to remember neoplasia as a complication of ureterosigmoidostomy. 


\section{Acknowledgments}

I am grateful to Mr Guy Baines for his help and encouragement and for his permission to publish these two cases; also to Mr T. F. Dee for the photographs. My thanks to Miss V. J. Barlow for her secretarial help.

\section{References}

Kille, J.N. \& Glick, S. (1967) Neoplasia complicating ureterosigmoidostomy. British Medical Journal, 4, 783.

Kozak, J.A., Watkins, W.E. \& Jewell, W.R. (1966) Neoplastic stomal obstruction: A complication of ureterosigmoidostomy. Journal of Urology, 96, 691 .

MACGregor, A.M.C. (1968) Muscus-secreting adenomatous polyp at the site of ureterosigmoidostomy: A case report and review of the literature. British Journal of Surgery, 55, 591.

Markowitz, A.M. \& Koontz, P. (1966) The development of colonic polyps at the site of ureteral implantation. Surgery, 60, 761 .
Marshall, S., Lyon, R.P. \& Minkler, D. (1966) Ureteral dilatation following use of oral contraceptives. Journal of the American Medical Association, 198, 782.

Oetjen, L.H., Campbell, J.L., Thomley, M.W. \& Parsons, R.L. (1970) Carcinoma of the colon following ureterosigmoidostomy. Journal of Urology, 104, 536.

RichteR, R.M. \& Ginsberg, S.A. (1967) Late development of colonic carcinoma complicating ureterosigmoidostomy. American Journal of Surgery, 113, 843.

ScotT, W.W. \& Boyd, H.L. (1953) Study of carcinogenic effect of betanaphthylamine on normal and substituted isolated sigmoid loop bladder of dogs. Journal of Urology, $70,914$.

Sommo, G. \& Traverso, G.B. (1968) Histochemical changes in the rectal mucosa after ureterosigmoidostomy. Pathologica, 59, 447.

Urdaneta, L.F., Duffell, D., Creevy, C.D. \& Aust, J.B. (1966) Late development of primary carcinoma of the colon following ureterosigmoidostomy: Report of three cases and literature review. Annals of Surgery, 164, 503.

Whittaker, R.H., Pugh, R.C.B.\& Dow, D. (1971) Colonic tumours following ureterosigmoidostomy. British Journal of Urology, 43, 562.

\section{A neonatal complication of maternal leukaemia treated with 6-mercaptopurine}

\author{
J. B. MCCONNELL \\ M.B., D.C.H.
}

\author{
R. BHOOLA \\ M.B.
}

\section{Department of Medicine, King Edward VIII Hospital, Durban, S. Africa}

\begin{abstract}
Summary
A 24-year-old African mother, who had received 6-mercaptopurine for acute leukaemia from before conception and throughout her pregnancy is described. The child, born prematurely, was anaemic at birth, with many features of a micro-angiopathic haemolytic anaemia. It is suggested that the mother's disease or treatment was involved in the aetiology of this anaemia.
\end{abstract}

\section{Introduction}

Acute leukaemia is uncommon in females of child-bearing age. Most cases associated with pregnancy are diagnosed during the pregnancy, usually after the first trimester (Hoover \& Schumacher, 1966). We can find reports of only four patients who had been receiving cytotoxic drugs at the time of conception (Merskey \& Rigal, 1956; Parekh, Shah \& Sharma, 1959; Rothberg, Conrad \&

Correspondence: J. B. McConnell, Royal Belfast Hospital for Sick Children, Belfast.
Cowley, 1959; Frenkel and Meyers, 1960). In only two (Parekh et al., 1959; Frenkel \& Meyers, 1960) was the drug continued for the duration of the pregnancy.

We report the case of an infant of a mother who received 6-mercaptopurine from before conception until delivery. The child had an abnormal blood picture from birth. This feature has not been reported before in an infant of a leukaemic mother.

\section{Case history}

A 24-year-old African primigravida presented in November 1969 with excessive bleeding after tooth extraction. A peripheral blood examination revealed a picture of myeloblastic leukaemia, which was confirmed by marrow biopsy. Treatment was started with 6-mercaptopurine in a dose of $50 \mathrm{mg}$ twice daily.

A remission was induced and lasted until June 1970, when the patient was transferred to our care. She felt well and physical examination revealed no 